\title{
Isolation, Identification, and Characterization of a New Highly Pathogenic Field Isolate of Mycobacterium avium spp. avium
}

\author{
Liangquan Zhu*, Yong Peng, Junxian Ye, Tuanjie Wang, Zengjie Bian, Yuming Qin, \\ He Zhang and Jiabo Ding* \\ China Institute of Veterinary Drug Control, Beijing, China
}

Avian tuberculosis is a chronic, contagious zoonotic disease affecting birds, mammals, and humans. The disease is most often caused by Mycobacterium avium spp. avium $(M A A)$. Strain resources are important for research on avian tuberculosis and vaccine

OPEN ACCESS

Edited by:

Joy Scaria,

South Dakota State University,

United States

Reviewed by:

Kuldeep Dhama,

Indian Veterinary Research

Institute (IVRI), India

Shankar Thangamani,

Midwestern University,

United States

${ }^{*}$ Correspondence:

Liangquan Zhu

1367391894@qq.com;

Jiabo Ding

dingjiabo@126.com

Specialty section:

This article was submitted to Veterinary Infectious Diseases,

a section of the journal

Frontiers in Veterinary Science

Received: 13 September 2017 Accepted: 20 December 2017

Published: 15 January 2018

Citation:

Zhu L, Peng Y, Ye J, Wang T, Bian Z,

Qin Y, Zhang H and Ding J (2018) Isolation, Identification, and

Characterization of a New

Highly Pathogenic Field Isolate of

Mycobacterium avium spp. avium.

Front. Vet. Sci. 4:243.

doi: 10.3389/fvets.2017.00243 development. However, there has been little reported about the newly identified MAA strain in recent years in China. In this study, a new strain was isolated from a fowl with symptoms of avian tuberculosis by bacterial culture. The isolated strain was identified to be MAA by culture, staining, and biochemical and genetic analysis, except for different colony morphology. The isolated strain was Ziehl-Zeelsen staining positive, resistant to p-nitrobenzoic acid, and negative for niacin production, Tween-80 hydrolysis, heat stable catalase and nitrate production. The strain had the DnaJ gene, IS1245, and IS901, as well. Serum agglutination indicated that the MAA strain was of serotype 1. The MAA strain showed strong virulence via mortality in rabbits and chickens. The prepared tuberculin of the MAA strain had similar potency compared to the MAA reference strain and standard tuberculin via a tuberculin skin test. Our studies suggested that this MAA strain tends to be a novel subtype, which might enrich the strain resource of avian tuberculosis.

Keywords: avian tuberculosis, Mycobacterium avium spp. avium, isolation, identification, characterization

\section{INTRODUCTION}

Avian tuberculosis is a serious, chronic infectious zoonotic disease in poultry, pet, or captive birds, animals, and humans that is caused by Mycobacterium avium spp. avium (MAA), a subspecies of the M. avium complex (MAC). Avian tuberculosis was classified as a List B disease by the World Organization for Animal Health and as a third-class animal disease in China. Clinical manifestations in birds include emaciation, depression, and diarrhea, and the prominent feature is the formation of caseous tubercular nodules and granulomas with calcification in the liver, spleen, intestine, and bone marrow (1-3). Humans exposed to infected birds may acquire a zoonotic infection, particularly in immunocompromised people such as those with $\operatorname{HIV}(3,4)$. Once fowls in poultry farms are infected, avian tuberculosis can persist for a long time and is difficult to eradicate, due to the chronic carrier state and shedding of bacteria by infected fowls $(5,6)$. This disease can have a serious economic impact associated with mortality, morbidity, and a reduction of egg production $(1,6)$. The best way is to quarantine and slaughter the infected ones $(6,7)$, as well as antibiotic treatment with the infected individuals $(8,9)$. 
The MAC is a group of closely related non-tuberculous mycobacterial species and subspecies which includes both veterinary and opportunistic human pathogens. In addition to birds, MAC may also infect different animal species, such as swine, cattle, deer, sheep, goat, horses, cats, dogs, and exotic species. The species within MAC are divided into the following subspecies according to taxonomical classification: $M A A$, the etiological agent of avian tuberculosis; M. avium spp. paratuberculosis, the etiological agent of Johne's disease; $M$. avium spp. silvaticum, previously called "wood pigeon Mycobacterium"; M. avium spp. hominissuis, frequently isolated from pig and human and M. intracellulare, a closely related pathogen of birds with a lower prevalence $(2,6,10)$. Although the subspecies of MAC differ greatly in their host range and growth potential, it has been reported that tuberculous lesions caused by MAA, M. avium spp. paratuberculosis, M. avium spp. hominissuis, and M. avium spp. silvaticum are indistinguishable (11-15). In addition, coinfection with different members of $\mathrm{M}$. tuberculosis complex and M. avium subspecies or with other mycobacterial species combinations is not rare in animal and human hosts $(16,17)$. Accurate identification and discrimination of mycobacterial species and subspecies is essential to determine their significance, pathogenicity, diagnosis, epidemiology, and most beneficial control program (18-20).

The identification and preservation of microbial strains is an important strategic resource for disease epidemiology research and disease prevention. Since the first report of avian tuberculosis in 1978 in China, there have been additional reports about the disease (7). As known, avian tuberculosis is sporadic and has a low incidence. Recent years, there were reports about incidence of avian disease in the poultry farm, but not large scale occurrences of disease $(7,21,22)$. Isolation and identification of $M A A$ strains from pathological materials could provide abundant resources for avian tuberculosis research. Although more attention has recently been paid to avian tuberculosis research, fewer MAA strains have been isolated and identified in recent years because of the high biological safety risks and low economic value of MAA strains in China. There were almost no reports regarding the isolation of $M A A$ strains from diseased species, and no systematic studies were carried out on the characteristics of $M A A$ strains.

In this work, we first isolated an $M A A$ strain from the typical tubercular nodules of a fowl with possible avian tuberculosis symptoms. We then systematically identified the isolated strain via a series of assays and further investigated the virulence and potency of the identified strain.

\section{MATERIALS AND METHODS}

\section{Ethics Statement}

The present study was approved by the Laboratory Animal Ethics Committee of China Institute of Veterinary Drug Control and was also approved by the Ministry of Agriculture and the Bureau of Animal Husbandry. The experiments were performed in compliance with the "Regulations of the People's Republic of China on the Administration of Experimental Animals" and the "Guidelines for the ethical review of experimental animal welfare in Beijing."
Mycobacterium avium spp. avium strains were cultured in an air-conditioned, air filtered, biosafety level III facility. The experimental use of serum samples, including sample collection, handling, testing, and personal protection, complied with the General Requirements for Laboratory Biological Safety of China, GB19489 (2008).

\section{MAA Strains}

Mycobacterium avium spp. avium strains CVCC275, CVCC276, and CVCC277 were the virulent reference strains for serotype 1, serotype 2, and serotype 3, respectively. MAA strain CVCC68201 was the virulent strain for avian tuberculin purified protein derivative (PPD) production and inspection (23).

\section{Tissue Origin and Examination}

One fowl showing the clinical signs (swollen joints, lameness, emaciation, tubercle formation under the skin, and granulomas in the conjunctival sac) of avian tuberculosis and poor health was transferred to the avian diseases section, Shandong Agricultural University, College of Animal Science and Veterinary Medicine. The fowl was euthanized and underwent a necropsy examination, and tissue containing typical tubercles was collected in $50 \mathrm{~mL}$ screw cap containers, packed in dry ice chambers, and then sent to the China Institute of Veterinary Drug Control.

After thawing the tissue samples, portions were formalin fixed, embedded in paraffin blocks, and stained by the Ziehl-Neelsen (Z-N) technique to detect Mycobacteria (24). An additional tissue sample was fixed in neutral-buffered formalin and embedded in paraffin wax. Thereafter, the sample was sectioned, stained and transported to perform histopathological examination.

\section{Mycobacterial Isolation}

Approximately $1 \mathrm{~g}$ of tissues were pooled into a test tube containing $1 \mathrm{~mL}$ of sterile PBS and homogenized for $1 \mathrm{~min}$. Two hundred microliters of the mixture was inoculated onto two slopes of Petragnani medium (25). The inoculated slopes were incubated at $37^{\circ} \mathrm{C}$ for 4 weeks. Colony morphology was visualized with the naked eye.

\section{Grown Colony Staining}

The grown colony on the slope was checked by Gram staining and Z-N acid-fast staining $(24,26)$. The studies were carried out using a Gram-staining kit and Z-N staining kit (Land Bridge Technology Co., Ltd., Beijing, China) according to the manufacturer's instructions. The colony, confirmed to contain Grampositive bacteria and acid-fast bacteria (AFB), was streaked out for further study.

\section{Biochemical Identification of the AFB Isolates}

Biochemical identification of the AFB isolates was based on multiple tests, which included the p-nitrobenzoic acid (PNB) growth assay, niacin production, Tween- 80 hydrolysis, heat stable catalase activity, and nitrate reductase activity $(27,28)$. 


\section{PNB Growth Assay}

The AFB isolates were screened by a growth test on a slope of Petragnani medium containing $500 \mu \mathrm{g} / \mathrm{mL}$ PNB (29). The inoculated slope was incubated at $37^{\circ} \mathrm{C}$ for 4 weeks, and then growth conditions were visualized.

\section{Niacin Production Assay}

The AFB isolates were washed off from the slope of Petragnani medium. Next, $0.9 \mathrm{~mL}$ of bacterial suspension was added to $0.2 \mathrm{~mL}$ of $3 \%$ benzidine ethanol, followed by the addition of $0.2 \mathrm{~mL}$ of $10 \%$ hydrogen bromide. The color reaction and precipitation reaction were observed.

\section{Tween-80 Hydrolysis Assay}

The Neutral Red/Tween- 80 solution was prepared by adding $0.5 \mathrm{~mL}$ of $0.8 \%$ Neutral Red to $100 \mathrm{~mL}$ of $0.5 \%$ Tween-80/PBS solution ( $\mathrm{pH} 7.0$ ), followed by sterilization at $116^{\circ} \mathrm{C}$ for $20 \mathrm{~min}$. The AFB isolates were washed off from the slope and resuspended to a final concentration of $10 \mathrm{mg} / \mathrm{mL}$ with PBS. Then, $0.5 \mathrm{~mL}$ of bacterial suspension was added to $2 \mathrm{~mL}$ Neutral Red/Tween- 80 solution and incubated at $37^{\circ} \mathrm{C}$ for 10 days. The color change of the Neutral Red/Tween-80 solution was observed daily.

\section{Heat Stable Catalase Assay}

First, $0.5 \mathrm{~mL}$ of the bacterial suspension prepared above $(10 \mathrm{mg} / \mathrm{mL})$ was added to a test tube and incubated at $68^{\circ} \mathrm{C}$ for $20 \mathrm{~min}$. Then, $0.5 \mathrm{~mL}$ of $30 \% \mathrm{H}_{2} \mathrm{O}_{2}$ in $10 \%$ Tween- 80 (pH 7.0) was added to the bacterial culture. The evolution of $\mathrm{O}_{2}$ gas caused frothing indicative of catalase activity, whereas the absence of $\mathrm{O}_{2}$ gas bubbles demonstrated a loss of enzymatic activity.

\section{Nitrate Reductase Assay}

Nitrate reduction was performed by the classical procedure with liquid reagent. First, $10 \mathrm{mM} \mathrm{NaNO}_{3} / \mathrm{PBS}$ solution ( $\mathrm{pH}$ 7) was prepared and sterilized at $116^{\circ} \mathrm{C}$ for $20 \mathrm{~min}$. Next, $0.5 \mathrm{~mL}$ of the bacterial suspension prepared above $(10 \mathrm{mg} / \mathrm{mL})$ was added to $2 \mathrm{~mL}$ of $\mathrm{NaNO}_{3} / \mathrm{PBS}$ solution. The mixture was incubated at $37^{\circ} \mathrm{C}$ for $2 \mathrm{~h}$, followed by the addition of $100 \mu \mathrm{L}$ of $18 \% \mathrm{HCl}$ and $100 \mu \mathrm{L}$ of $0.2 \%$ sulfanilamide solution and later by $100 \mu \mathrm{L}$ of $0.1 \%$ naphthylethylenediamine solution. The system was stored at $2-8^{\circ} \mathrm{C}$ for 2 weeks, and the color reaction was visualized.

\section{Genetic Identification of the AFB Isolates}

The AFB isolates were examined by PCR for the detection of DnaJ, IS1245, and IS901 gene fragments (30). The colony on Petragnani medium was washed off from the slope and washed with PBS. After heat inactivation at $60^{\circ} \mathrm{C}$ for $2 \mathrm{~h}$, genomic DNA was extracted using a genomic DNA purification kit (Promega, Madison, WI, USA). Primers were designed for amplification of DnaJ, IS1245, and IS901 fragments (Table 1) (30). Multiplex PCR was programmed as 1 cycle at $96^{\circ} \mathrm{C}$ for $2 \mathrm{~min}, 35$ cycles at $96^{\circ} \mathrm{C}$ for $10 \mathrm{~s}, 58^{\circ} \mathrm{C}$ for $10 \mathrm{~s}, 72^{\circ} \mathrm{C}$ for $1 \mathrm{~min}$, and $1 \mathrm{cycle}$ at $72^{\circ} \mathrm{C}$ for $2 \mathrm{~min}$. The PCR products were visualized by DNA gel electrophoresis.
TABLE 1 | The PCR primers used to identify the acid-fast bacteria isolates.

\begin{tabular}{llc}
\hline Gene & Sequence of primer & Length of PCR product (bp) \\
\hline DnaJ & 5'-GACTTCTACAAGGAGCTGGG-3' & 140 \\
& 5'-GAGACCGCCTTGAATCGTTC-3' & \\
IS1245 & 5'-GAGTTGACCGCGTTCATCG-3' & 385 \\
& 5'-CGTCGAGGAAGACATACGG-3' & \\
IS901 & 5'-GGATTGCTAACCACGTGGTG-3' & 577 \\
& 5'-GCGAGTTGCTTGATGAGCG-3' & \\
\hline
\end{tabular}

\section{Serological Identification of the AFB Isolates}

The serotype of the AFB isolates was identified by the serum agglutination method as described below (31). The antigens of serotype 1,2, and 3 were prepared from MAA reference strains CVCC275, CVCC276, and CVCC277, respectively. The AFB isolates, as well as the three strains, were cultured on LowensteinJensen solid medium at $37^{\circ} \mathrm{C}$ for 18 days. The bacteria were washed off using $200 \mathrm{~mL}$ of sterile PBS containing sterile glass beads and inactivated at $37^{\circ} \mathrm{C}$ for 7 days with shaking up to four times a day. The mixture was centrifuged to remove the supernatant. After washing three times, the bacterial pellet was suspended in $0.4 \%$ sodium citrate/PBS to a concentration of approximately $10^{10} \mathrm{CFU} / \mathrm{mL}$. The suspended bacteria were used as antigen for the serum agglutination assay.

The AFB isolates were cultured on Petragnani medium at $37^{\circ} \mathrm{C}$ for 4 weeks. The bacterial culture was washed off using sterile PBS containing sterile glass beads and centrifuged at 10,000 rpm for $5 \mathrm{~min}$ to remove the supernatant. The bacterial pellet was weighed and resuspended in sterile PBS to a concentration of $0.1 \mathrm{mg} / \mathrm{mL}$. Three 8-week-old SPF chickens were inoculated intravenously with $0.2 \mathrm{~mL}$ of the above bacterial suspension, with the same amount of PBS as a control. After 60 days, sera were collected from the wing vein for the serum agglutination assay.

For the serum agglutination assay, one drop of serum from the wing vein and one drop of bacterial suspension were mixed on a slide. After $1 \mathrm{~min}$, the results were graded as negative (-), weakly positive $(+)$, positive $(++)$, and strongly positive $(+++)$, according to agglutination degree as no agglutination ( - ), less than $25 \%$ agglutination (+), approximately $50 \%$ agglutination $(++)$, and more than $75 \%$ agglutination $(+++)$, respectively.

\section{Virulence}

The AFB isolates were cultured on Petragnani medium at $37^{\circ} \mathrm{C}$ for 4 weeks. The bacterial culture was washed off using sterile PBS and centrifuged at $10,000 \mathrm{rpm}$ for $5 \mathrm{~min}$ to remove the supernatant. The bacterial pellet was weighed. The virulence of the AFB isolates in rabbits and chickens was studied according to the "The People's Republic of China veterinary biological product regulation" (25).

For virulence in rabbits, the above bacterial pellet was resuspended in sterile PBS to a final concentration of $0.5,1,2$, or $4 \mathrm{mg} / \mathrm{mL}$. Six healthy rabbits at $2 \mathrm{~kg}$ of body weight (Albino, Vital River) were inoculated intravenously in the ear with $1 \mathrm{~mL}$ of the bacterial suspension, while the same amount of PBS was used as a control. The inoculated rabbits were observed for 30 days, and survival was recorded. 
For virulence in chickens, the above bacterial pellet was resuspended in sterile PBS to a final concentration of $0.5,1.25,2.5$, or $5 \mathrm{mg} / \mathrm{mL}$. Five 8-week-old SPF chickens (Vital River) were inoculated intravenously with $0.2 \mathrm{~mL}$ of the bacterial suspension, while the same amount of PBS was used as a control. The inoculated rabbits were observed for 60 days, and survival was recorded.

\section{Potency and Specificity}

\section{Preparation of PPD of Avian Tuberculin}

Avian tuberculin was prepared according to the rules for tuberculin production and inspection (25), as described briefly below. The AFB isolates were streaked out from the Petragnani slope medium to $200 \mathrm{~mL}$ of Sauton liquid medium and grown at $37^{\circ} \mathrm{C}$ for 40-45 days to prepare the seed strain. The seed strain was inoculated into $1,000 \mathrm{~mL}$ of Sauton liquid medium and grown at $37^{\circ} \mathrm{C}$ for 90 days. The culture was inactivated at $121^{\circ} \mathrm{C}$ for $30 \mathrm{~min}$ and filtered through a hollow fiber membrane to remove the bacteria. The filtrate was mixed with $40 \%(\mathrm{w} / \mathrm{v})$ TCA solution to a final concentration of $4 \%$. The mixture was incubated overnight at $2-8^{\circ} \mathrm{C}$. The pellets were collected and washed three times with $1 \%$ TCA solution. The pellets were centrifuged at $4^{\circ} \mathrm{C}, 5,000 \mathrm{rpm}$ for $30 \mathrm{~min}$, and the pellet was dried and weighed. The pellet was dissolved in $1 \mathrm{M} \mathrm{NaOH}$, adjusted to $\mathrm{pH} 7.4$ using $1 \mathrm{M} \mathrm{HCl}$, and filtered through sterilizing Chua's filter. The final product was the avian tuberculin PPD for further testing, referred to as PPD-AFB. The avian tuberculin PPD from CVCC68201 (PPD-CVCC68201) was prepared using the same procedure.

\section{Preparation of Allergen and Sensitization of Guinea Pigs}

Mycobacterium avium spp. avium strain CVCC68201 was cultured at $37^{\circ} \mathrm{C}$ for 20 days. The bacteria were scraped from the slope, weighed, dissolved in sterile PBS, and inactivated at $121^{\circ} \mathrm{C}$ for $30 \mathrm{~min}$. The bacterial suspension was mixed with Fruend's incomplete adjuvant to prepare an emulsion at a concentration of $40 \mathrm{mg} / \mathrm{mL}$ bacteria. The emulsion was subpackaged and inactivated at $80^{\circ} \mathrm{C}$ water bath for $2 \mathrm{~h}$, and the emulsion was used as the allergen. Sixteen guinea pigs at $400 \mathrm{~g}$ of body weight (Hartly, Vital River) were sensitized with $0.5 \mathrm{~mL}$ of allergen by deep intramuscular injection in the inner thigh and maintained for 35 days under specific pathogen-free conditions. After the sensitization period, guinea pigs were shaved in a $3 \mathrm{~cm}^{2}$ area on the hip, at the opposite side of allergen injection. The standard avian tuberculin PPD (PPD-S, IVDC) was diluted 100-fold, and $0.1 \mathrm{~mL}$ diluted standard avian tuberculin PPD was injected into the shaved area of the guinea pigs. The diameter of reactions on the skin was measured after $24 \mathrm{~h}$, and the guinea pig was positive for sensitization if the area of skin thickness was over $1 \mathrm{~cm}^{2}$.

\section{Potency Calibration and Specificity Test of Avian Tuberculin PPD}

The potency calibration of PPD was carried out according to the relevant rules $(24-26,32)$. For the potency calibration, the PPD-AFB was diluted to two concentrations of 0.1 and 0.25 dose/ $\mathrm{mL}$. Additionally, the PPD-S and PPD-CVCC68201 were diluted to two concentrations of 100 and $250 \mathrm{IU} / \mathrm{mL}$. The shaved area of the sensitized guinea pigs was divided into two equal blocks. Each block contained three randomized injection sites resulting in six total injections, with a replicated injection of each PPD concentration in each guinea pig. Guinea pigs were injected intradermally with a volume of $0.1 \mathrm{~mL}$ of designated PPDs. A total of 12 guinea pigs ( 6 guinea pigs for each PPD concentration) were used for PPD inoculation. An additional 4 guinea pigs were used as negative controls. No adverse effect resulted from the procedures used, and the animals were monitored daily by the animal care staff. After $24 \mathrm{~h}$, the skin thickness was measured using Vernier calipers.

The specificity of PPD testing was performed as described below $(25,33)$. Six guinea pigs at $400 \mathrm{~g}$ of body weight (Hartly, Vital River) were shaved in an area $(3 \mathrm{~cm} \times 9 \mathrm{~cm})$ on both sides of the chest. PPD-AFB, PPD-S, and PPD-CVCC68201 were diluted to $2 \times 10^{4} \mathrm{IU} / \mathrm{mL}$. Similar to the potency test, the guinea pigs were injected intradermally with one volume of $0.1 \mathrm{~mL}$ of designed PPDs with replicated injections of each PPD. After 24 h, the skin inflammatory reaction was observed.

\section{Statistical Analysis}

The statistical package SPSS and one-way ANOVA method were used for data analyses. The results were expressed as the mean \pm SD. The $p$-values were considered significant at $\left({ }^{*} p<0.05\right)$.

\section{RESULTS}

\section{Identification of the Pathological Tissue}

The pathological tubercle contained a yellow-white cheese-like substance with a coated envelope after cutting. After smearing and Z-N staining, a large number of mycobacteria were observed (data not shown). With further histopathological examination of the tubercle, caseous necrosis appeared in the center of the tubercle with a large number of lymphoid cells, epithelioid cells, and Langerhans multinucleated giant cells (Figure 1A). This was a typical avian tuberculosis symptom.

On the slopes of the Petragnani medium inoculated with homogenized tissue, transparent, round, thick, drip-like colonies were observed (Figure 1B, arrow) after incubation at $37^{\circ} \mathrm{C}$ for 4 weeks. The colonies did not have a yellowish-white, cream like appearance $(24,25,34)$. While streaking, the colonies had a threadlike filament (data not shown). The colonies were further tested by Gram staining and Z-N staining. As shown in Figure 1C, the colonies were Gram-positive, bluish-purple staining, and contained straight or curved rod-shaped bacteria. Additionally, the grown colonies were Z-N staining positive with red staining and a length of 1-3 $\mu \mathrm{m}$ (Figure 1D). The above results indicated that the colonies were AFB, i.e., mycobacteria.

\section{Biochemical Characterization of AFB Isolates}

Five different biochemical tests, including resistance to PNB, niacin production, Tween- 80 hydrolysis, heat stable catalase and nitrate production, were applied to the AFB isolates (Table 2). The AFB isolates showed positive results for resistance to PNB. For the niacin production test, a clear pellet, not a peach red pellet 

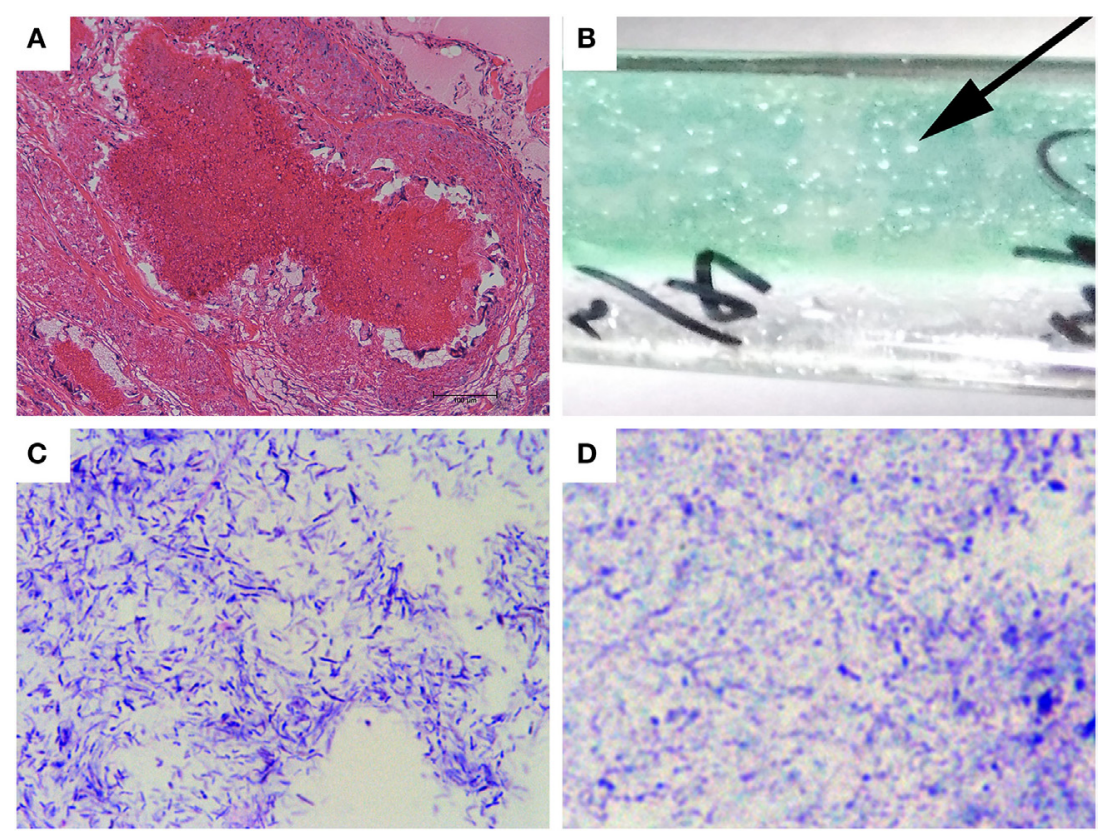

FIGURE 1 | Tubercle staining and mycobacterial isolation. (A) Histopathological staining of the pathological tubercle from the diseased fowl. Bar, 100 um. (B) Growth of isolated mycobacteria colonies from the tissue homogenate on a slope of Petragnani medium. The arrow indicates a typical clone.

(C,D) Photographies of the mycobacterial colonies after Gram staining (C) and Z-N acid-fast staining [(D), 1,000×].

TABLE 2 | Distinguishing characteristics of the acid-fast bacteria (AFB) isolates.

\begin{tabular}{|c|c|c|c|c|c|}
\hline Characteristics & Resistant to p-nitrobenzoic acid & Niacin production & Tween-80 hydrolysis & Catalase at $68^{\circ} \mathrm{C}$ & Nitrate reduction \\
\hline AFB isolates & + & - & - & - & - \\
\hline
\end{tabular}

was observed, indicating a negative result. The test for Tween-80 hydrolysis was negative, indicated by no color change of from neutral red. The heat stable catalase activity was negative, as no bubble was generated in the reaction solution. The reaction system was very light pink, suggesting the absence of nitrate reductase in the AFB isolates. From the above biochemical tests, the AFB isolates most closely resemble $M A A$ in their enzymatic activities.

\section{Genetic Characterization of AFB Isolates}

Using multiplex PCR, the AFB isolates and the CVCC6801 strain produced three bands $(140,385$, and $577 \mathrm{bp}$ ) corresponding to the DnaJ gene, IS1245, and IS901 (Figure 2). As the isolates were $I S 901+, I S 1245+$, and dnaJ+ $(30,35)$, the isolates were of the $M A A$ strain.

\section{Serological Characterization of AFB Isolates}

The MAA strain has three serotypes: serotype 1 , serotype 2 , and serotype 3 (2). Using the serum agglutination method, the antigen prepared from AFB isolates showed a strong agglutination reaction to the serum from chickens infected with the CVCC275 strain but no agglutination reaction to the serum from chickens infected with the CVCC276 and CVCC277 strains (Table 3).
The MAA strains CVCC275, CVCC276, and CVCC277 were the reference strains for serotype 1, serotype 2, and serotype 3 , respectively. The results suggested that the AFB isolates were an MAA strain of serotype 1 .

\section{Virulence of the AFB Isolates}

To evaluate the virulence of the AFB isolates, mortality in rabbits and chickens was recorded during the observation period postinjection of the prepared bacteria. As shown in Figure 3A, the six uninfected rabbits remained healthy and alive until the 30th day of the observation period. Among the six rabbits injected with $0.5 \mathrm{mg}$ of bacteria, three of the rabbits died, and three remained alive until the end of the observation period. For the remaining three groups of rabbits inoculated with 1,2, and $4 \mathrm{mg}$ of bacteria, all rabbits died during the observation period. Moreover, the rabbits died at earlier dates when inoculated with higher doses of bacteria.

As shown in Figure 3B, the five uninfected chickens remained healthy and alive until the 60th day of the observation period. All of the chickens in the groups injected with different doses of bacteria, from 0.1 to $1.0 \mathrm{mg}$, died during the 60 days observation period. Additionally, the chickens died earlier when given a higher inoculation dose of bacteria. 


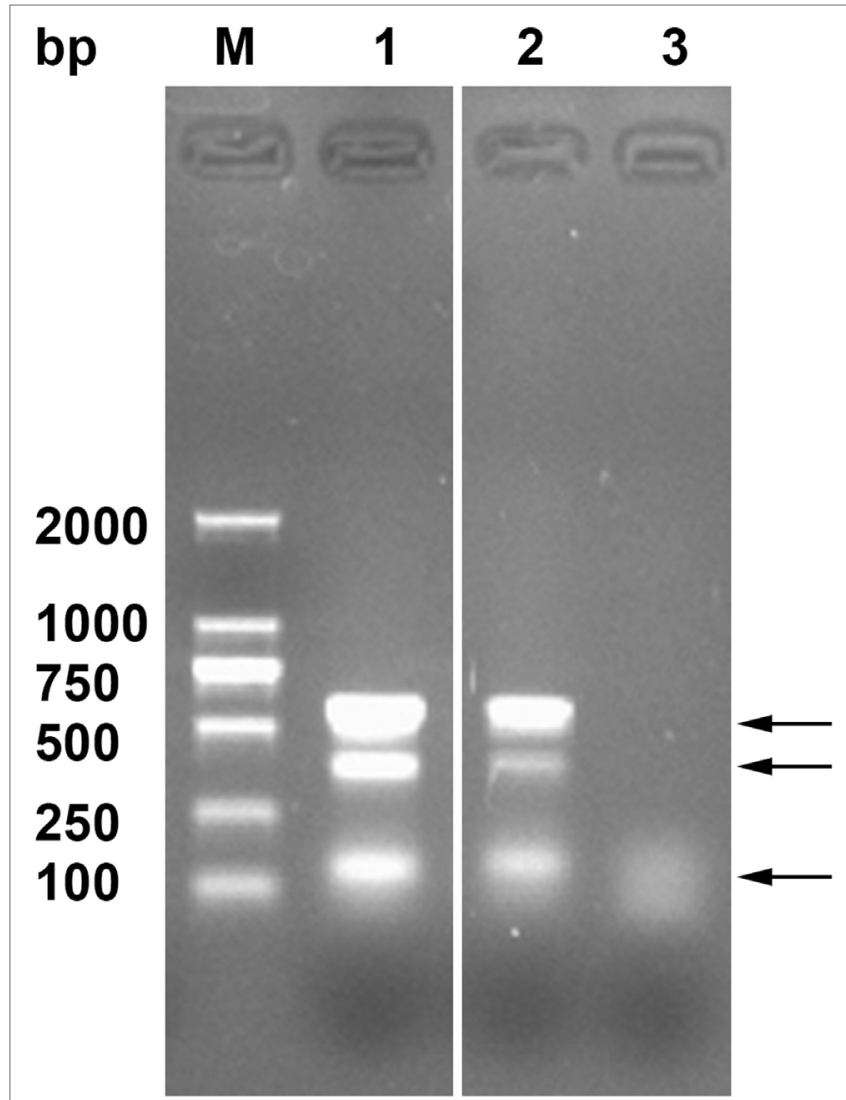

FIGURE 2 | Genetic identification of the acid-fast bacteria (AFB) isolates by Multiplex PCR. Lane M, DNA ladder, Lane 1, AFB isolates, Lane 2, CVCC68201, and Lane 3, PBS. The arrows indicate the three typical amplified bands of DnaJ gene, IS1245, and IS901.

TABLE 3 | Serotype identification of the acid-fast bacteria (AFB) isolates.

\begin{tabular}{|c|c|c|c|}
\hline & \multicolumn{3}{|c|}{ Antigen prepared from } \\
\hline & CVCC275 & CVCC276 & CVCC277 \\
\hline $\begin{array}{l}\text { Sera }{ }^{a} \text { from the AFB } \\
\text { isolates inoculated } \\
\text { chicken }\end{array}$ & +++ & - & - \\
\hline
\end{tabular}

aThe sera from three inoculated chicken was all tested and showed same result.

According to the definition of $M A A$ virulence (25), the results indicated that the AFB isolates were $M A A$ strain with strong virulence.

\section{Potency and Specificity of the PPD Prepared from AFB Isolates}

The potency of the AFB isolates was evaluated by calibrating the prepared avian tuberculin PPD from the AFB isolates. As shown in Figure 4, PPD-AFB, PPD-S and PPD-CVCC68201 showed no significant difference when analyzed for indurations (skin thickness) in sensitized guinea pigs. Thus, the PPD prepared from the AFB isolates had a similar potency to the standard PPD and the
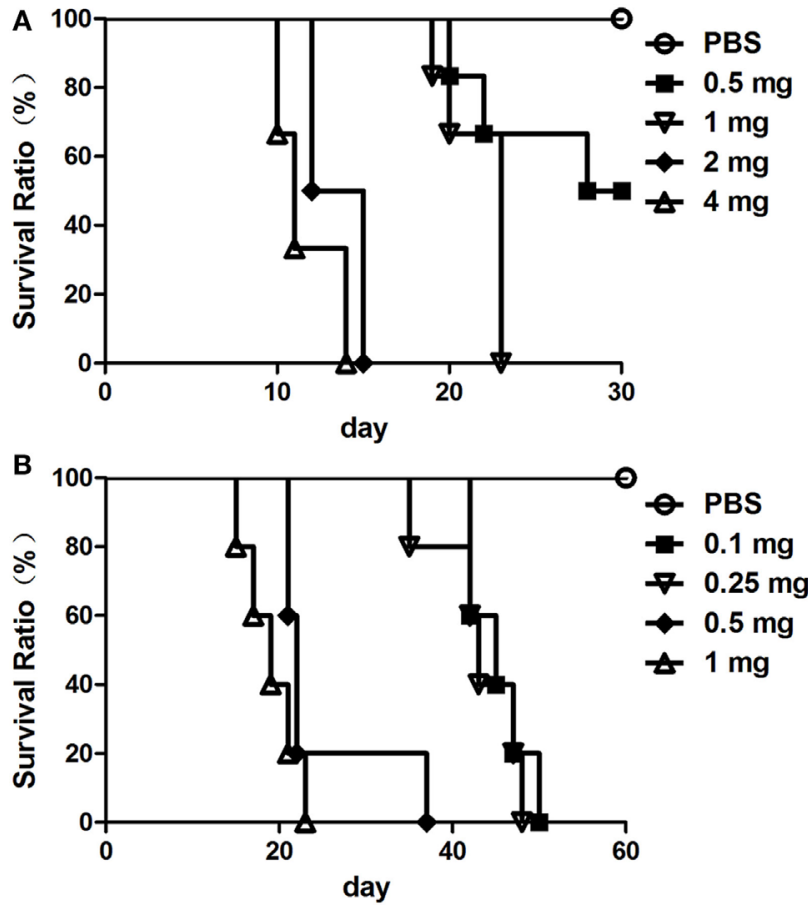

FIGURE 3 | The virulence of the acid-fast bacteria (AFB) isolates. Five groups of healthy rabbit (A) and chicken (B) was inoculated with different amounts of Mycobacterium avium spp. avium bacteria. The virulence of the AFB isolates is represented by the survival ratio of rabbits (A) and chickens (B).

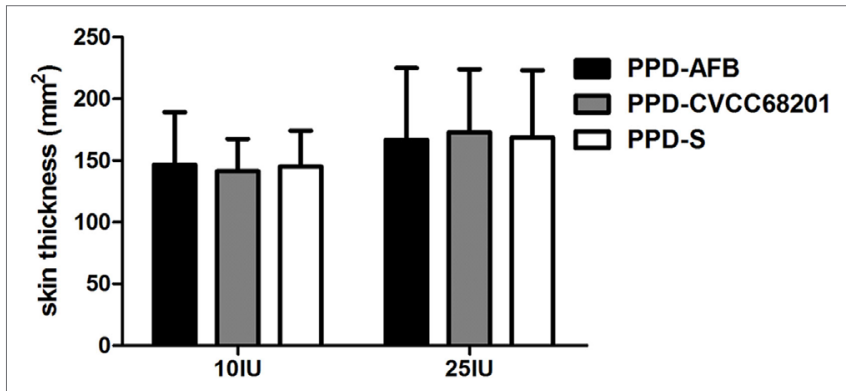

FIGURE 4 | The potency of the acid-fast bacteria (AFB) isolates. The purified protein derivative (PPD) was prepared from the AFB isolates and was calibrated by traditional PPD skin test. The potency is represented by the area of skin thickness after PPD injection on sensitized guinea pigs.

TABLE 4 | Specificity of the p-nitrobenzoic acid (PPD) prepared from the acid-fast bacteria isolates.

\begin{tabular}{lccc}
\hline PPD & Testing-PPD & PPD-S & PPD-CVCC68201 \\
\hline Skin inflammatory reaction & - & - & -
\end{tabular}

PPD from the reference $M A A$ strain, and the AFB isolates had a similar potency to the reference $M A A$ strain.

The specificity of the AFB isolates was analyzed by the skin test in unsensitized guinea pigs with PPD-AFB, PPD-CVCC68201, and PPD-S. Similar to PPD-CVCC68201 and PPD-S, PPD-AFB could not induce a skin inflammatory reaction (Table 4). Thus, 
the PPD prepared from the AFB isolates was specific for PPD prepared from the $M A A$ strains.

\section{DISCUSSION}

In this work, we isolated an MAA strain from caseous tubercular nodules of a fowl with avian tuberculosis. The isolated strain was a typical MAA strain of serotype 1, genotype IS901+ and IS1245+ according to biochemical, serological and genetic identification. The identified MAA strain was a virulent strain and showed similar PPD potency as the reference $M A A$ strain. Interestingly, our study revealed that this isolated $M A A$ strain showed a novel colony appearance not previously reported.

Diagnosis of avian tuberculosis is frequently based on clinical symptoms, postmortem gross lesions and Z-N staining of the smear. However, Z-N staining for demonstrating acid-fast bacilli is limited because of its low sensitivity and detection rate (36). Serological diagnosis method such as hemagglutination, complement fixation, ELISA, and Western-blot analysis might be most useful in late-stage infections based on the process of mycobacteria evading the host immune system. Also the request of specific antigen might limit the board application of these methods (37). The PCR approaches, including PCR, multiplex PCR, PCR restriction fragment length polymorphism (RFLP), and mycobacterial interspersed repetitive units and variable number tandem repeats (MIRU-VNTR) typing are also capable of specifically detecting DNA fragments, thus acting as a diagnostic procedure (30, 35, $38,39)$. However, PCR products can have false positive results because of contamination (40). The PPD skin test is the only method recommended by OIE, but the result reading is affected by the dose and injection manner (24). Comparing everything, the gold standard technique for avian tuberculosis is culturing from diseased tissue for isolation, genotypic and phenotypic characterization of the suspect pathogen (2). This method is reliable, but it requires more time and high quality culture medium.

For the conventional culturing technique of the $M A A$ strain, it is important to use the proper selective medium (41). It was reported that $M$. avium grows best on media such as LowensteinJensen medium, Herrold's medium and Middlebrook medium (6), which were also recommended by the World Organization for Animal Health as the culturing medium of MAA (24). In this study, we used Petragnani medium to isolate the MAA strain from the tubercle $(25,26)$. The Petragnani medium was reported to have similar colony yielding ratio as Lowenstein-Jensen medium for Mycobacterium tuberculosis (42). As known, culturing of mycobacteria is time-consuming to complete, as it takes at least $4-8$ weeks for visible colonies to appear $(5,37)$. For $M A A$ strain, the culture should be incubated for at least 12 weeks using Lowenstein-Jensen medium, Herrold's medium and Middlebrook medium (43). It took only 4 weeks to observe transparent, round, thick, drip-like colonies on Petragnani medium (Figure 1B). Thus, culturing Petragnani medium for isolation of $M A A$ strain was time-saving and offered greater efficiency for avian diagnosis.

The traditional method for species and subspecies typing of Mycobacterium was according to growth on distinct medium and morphology of the grown colony. The MAA strain usually had yellowish-white, round, and cream-like colonies (25) (Insights into the mycobacterium infection). In our study, the isolated $M A A$ strain had a novel colony appearance, as round, thick, drip-like colonies (Figure 1B). MAA forms colonies of different morphologies, including smooth transparent, smooth opaque, and rough, which might influence pathogenicity, virulence, drug susceptibility and macrophage survival (44-46). Here, this isolated $M A A$ strain had similar virulence and PPD potency compared to the MAA reference strain CVCC68201 (Figures 3 and 4). This finding might indicate that this isolated $M A A$ strain might be of a novel subtype and have differences in some unknown phenotype. However, the traditional method was limited in use because of the high biosafety requirement, and it was more time-consuming and required more complicated techniques. Genetic approaches would applied for further subtyping of this newly isolated $M A A$ strain, as RFLP and DNA sequencing of distinct gene cluster for subtyping of diverse $M A A$ isolates $(47,48)$, short sequence repeats sequencing and MIRU-VNTR typing for subtyping of M. avium spp. paratuberculosis (49-51). For example, IS901 RFLP typing was used to discriminate MAA field isolates $(52,53)$. As reported, a cluster of genes were proved to be related to colony morphology, such as MAP1156 (diacyglycerol O-acyltransferase), MAP 1152 (PPE protein), and Lsr2 etc. in M. avium spp.paratuberculosis (54), MAV_4334 (nitroreductase family protein), MAV_5106 (phosphoenolpyruvate carboxykinase), MAV_1778 (GTP-binding protein LepA), etc. in M. avium spp. hominissuis (55). In addition, glycopeptidolipids and its biosynthesis were reported to be related to the surface properties and colony morphology of mycobacteria (56-58). DNA sequencing of these gene clusters might give a clue for further subtyping of this isolated $M A A$ strain with a round, thick, drip like colony appearance (Figure 1B).

Virulence is a reflection of pathogenicity of the bacterial pathogen. The virulence of $M A A$ is affected by various factors and could change with different hosts and environments (59). The extent of intracellular replication in cell cultures, guinea pigs and mice is widely used as a measure for mycobacterial virulence $(60,61)$. Additionally, the mortality of animals inoculated with mycobacteria is also used as an indicator of virulence $(25,62)$. The definition of the MAA virulent strain is that inoculation of 0.1-1.0 mg bacteria would lead to the death of chickens or that $1 \mathrm{mg}$ of bacteria would lead to the death of rabbits $(23,25)$. The isolated MAA strain here was proven to have strong virulence (Figure 3). Compared to intracellular bacterial replication or macrophage infection $(59,63)$, it was more intuitive to use mortality as an indicator of virulence, especially for a bacterial pathogen of strong virulence.

In conclusion, in this study, we isolated and identified a strain of $M$. avium spp. avium. The virulence and the derivative PPD of the strain were also characterized. Our work provided a novel reference strain for the intensive study of avian tuberculosis. This work not only enriched strain resources for M. avium spp. avium but also provided a realistic candidate strain for further development of $M$. avium spp. avium vaccines.

\section{ETHICS STATEMENT}

The present study was approved by the Laboratory Animal Ethics Committee of China Institute of Veterinary Drug 
Control and was also approved by the Ministry of Agriculture and the Bureau of Animal Husbandry. The experiments were performed in compliance with the "Regulations of the People's Republic of China on the Administration of Experimental Animals" and the "Guidelines for the ethical review of experimental animal welfare in Beijing." MAA strains were cultured in an air-conditioned, air filtered, biosafety level III facility. The experimental use of serum samples, including sample collection, handling, testing, and personal protection, complied with the General Requirements for Laboratory Biological Safety of China, GB19489 (2008).

\section{REFERENCES}

1. Marco I, Domingo M, Lavin S. Mycobacterium infection in a captivereared capercaillie (Tetrao urogallus). Avian Dis (2000) 44:227-30. doi:10.2307/1592531

2. Saif YM, Fadly AM. Diseases of Poultry. Ames, Iowa: Blackwell Pub (2008).

3. Slany M, Ulmann V, Slana I. Avian mycobacteriosis: still existing threat to humans. Biomed Res Int (2016) 2016:4387461. doi:10.1155/2016/4387461

4. Martin G, Schimmel D. [Mycobacterium avium infections in poultry - a risk for human health or not?]. Dtsch Tierarztl Wochenschr (2000) 107:53-8.

5. Dhama K, Mahendran M, Tomar S. Avian tuberculosis: an overview. Poul Punch (2007) 24:38-52.

6. Dhama K, Mahendran M, Tiwari R, Dayal Singh S, Kumar D, Singh S, et al. Tuberculosis in birds: insights into the Mycobacterium avium infections. Vet Med Int (2011) 2011:712369. doi:10.4061/2011/712369

7. Wang X. Overview of avian tuberculosis in China. Guide to Chin Poul (2001) $18: 20-2$.

8. Buur J, Saggese MD. Taking a rational approach in the treatment of avian mycobacteriosis. Vet Clin North Am Exot Anim Pract (2012) 15:57-70,vi. doi:10.1016/j.cvex.2011.12.001

9. Saggese MD, Tizard I, Gray P, Phalen DN. Evaluation of multidrug therapy with azithromycin, rifampin, and ethambutol for the treatment of Mycobacterium avium subsp avium in ring-neck Doves (Streptopelia risoria): an uncontrolled clinical study. JAvian Med Surg (2014) 28:280-9. doi:10.1647/2012067R1

10. Rindi L, Garzelli C. Genetic diversity and phylogeny of Mycobacterium avium. Infect Genet Evol (2014) 21:375-83. doi:10.1016/j.meegid.2013.12.007

11. Mackintosh CG, De Lisle GW, Collins DM, Griffin JF. Mycobacterial diseases of deer. N Z Vet J (2004) 52:163-74. doi:10.1080/00480169.2004.36424

12. Turenne CY, Collins DM, Alexander DC, Behr MA. Mycobacterium avium subsp. paratuberculosis and M. avium subsp. avium are independently evolved pathogenic clones of a much broader group of M. avium organisms. J Bacteriol (2008) 190:2479-87. doi:10.1128/JB.01691-07

13. Agdestein A, Johansen TB, Kolbjornsen O, Jorgensen A, Djonne B, Olsen I. A comparative study of Mycobacterium avium subsp. avium and Mycobacterium avium subsp. hominissuis in experimentally infected pigs. BMC Vet Res (2012) 8:11. doi:10.1186/1746-6148-8-11

14. Ronai Z, Csivincsik A, Dan A, Gyuranecz M. Molecular analysis and MIRUVNTR typing of Mycobacterium avium subsp. avium, 'hominissuis' and silvaticum strains of veterinary origin. Infect Genet Evol (2016) 40:192-9. doi:10.1016/j.meegid.2016.03.004

15. Arrazuria R, Juste RA, Elguezabal N. Mycobacterial infections in rabbits: from the wild to the laboratory. Transbound Emerg Dis (2017) 64:1045-58. doi: $10.1111 /$ tbed. 12474

16. Sharma K, Sharma A, Modi M, Singh G, Kaur H, Varma S, et al. PCR detection of co-infection with Mycobacterium tuberculosis and Mycobacterium avium in AIDS patients with meningitis. JMed Microbiol (2012) 61:1789-91. doi:10.1099/jmm.0.045898-0

17. Arrazuria R, Sevilla IA, Molina E, Perez V, Garrido JM, Juste RA, et al. Detection of Mycobacterium avium subspecies in the gut associated lymphoid tissue of slaughtered rabbits. BMC Vet Res (2015) 11:130. doi:10.1186/ s12917-015-0445-2

\section{AUTHOR CONTRIBUTIONS}

LZ conceived and designed the experiments and wrote the whole manuscript. YP, JY, TW, ZB, and HZ provided assistance of the experiments. YQ revised the manuscript. JD supervised the experiments and revised the manuscript.

\section{FUNDING}

This work was supported by the National Key R\&D Program of China (2016YFD0500902).

18. Chiers K, Deschaght P, De Baere T, Dabrowski S, Kotlowski R, De Clercq D, et al. Isolation and identification of Mycobacterium avium subspecies silvaticum from a horse. Comp Immunol Microbiol Infect Dis (2012) 35:303-7. doi:10.1016/j.cimid.2012.01.011

19. Ahlstrom C, Barkema HW, Stevenson K, Zadoks RN, Biek R, Kao R, et al. Limitations of variable number of tandem repeat typing identified through whole genome sequencing of Mycobacterium avium subsp. paratuberculosis on a national and herd level. BMC Genomics (2015) 16:161. doi:10.1186/ s12864-015-1387-6

20. Sevilla IA, Molina E, Elguezabal N, Perez V, Garrido JM, Juste RA. Detection of mycobacteria, Mycobacterium avium subspecies, and Mycobacterium tuberculosis complex by a novel tetraplex real-time PCR assay. J Clin Microbiol (2015) 53:930-40. doi:10.1128/JCM.03168-14

21. Xu Q, Zhou S, Li Z, Bi D. Diagnosis of avian tuberculosis. Chin J Vet Sci (2001) 31:30-1. doi:10.3969/j.issn.1673-4696.2001.03.016

22. Zhang Y, Cai J, Shen Y. Diagnosis and therapy of avian tuberculosis. Poul Husbandry Dis Control (2002) 11:28-9.

23. China Institute of Veterinary Drug Control, China Veterinary Culture Collection Center. CVCC Catalogue of Culture. Beijing, China: China Agricultural Science and Technology Publishing Company (2008).

24. Office International Des Epizooties. OE Terrestrial Manual. Paris, France: Office International Des Epizooties (2014).

25. Ministry of Agriculture of the People's Republic of China. The People's Republic of China Veterinary Biological Product Regulation. Beijing, China: Chemical Industry Press (2000). p. 164-6.

26. General Administration of Quality Supervision, Inspection and Quarantine, People's Republic of China. Industry standard for import and export inspection and quarantine. In: Certification and Accreditation Administration of the Peoples Republic of China, editor. Quarantine Protocol for Animal Tuberculosis. Beijing: Standards Press of China (2011). p. 4-5.

27. Levy-Frebault VV, Portaels F. Proposed minimal standards for the genus Mycobacterium and for description of new slowly growing Mycobacterium species. Int J Syst Bacteriol (1992) 42:315-23. doi:10.1099/0020771342-2-315

28. Yang Z, Fang H. Human and Animal Pathogenic Bacteria. Shijiazhuang, Hebei: Hebei Science \& Technology Press (2003).

29. Sharma B, Pal N, Malhotra B, Vyas L. Evaluation of a rapid differentiation test for Mycobacterium tuberculosis from other mycobacteria by selective inhibition with P-nitrobenzoic acid using MGIT 960. J Lab Physicians (2010) 2:89-92. doi:10.4103/0974-2727.72157

30. Moravkova M, Hlozek P, Beran V, Pavlik I, Preziuso S, Cuteri V, et al. Strategy for the detection and differentiation of Mycobacterium avium species in isolates and heavily infected tissues. Res Vet Sci (2008) 85:257-64. doi:10.1016/j. rvsc. 2007.10 .006

31. Chen X, Mao K, Luo Y. Diagnosis of avian tuberculosis with the avian Tubercula plain agglutination test. Chin J Vet Drug (1999) 33:3-5.

32. General Administration of Quality Supervision, Inspection and Quarantine, People's Republic of China. National standards of the People's Republic of China. In: National Technical Standardization Committee of Animal Inspection and Quarantine, editor. Diagnostic Techniques for Tuberculosis of Animal. Beijing: General Administration of Quality Supervision, Inspection and Quarantine (2002). p. 181-82. 
33. Haifeng $X$. Testing method for the specificity of purified protein derivative. Chin J Vet Drug (1990) 24:15-8.

34. Mahon CR, Lehman DC, Manuselis G. Textbook of Diagnostic Microbiology. Maryland Heights, MO: Saunders (2011).

35. Bartos M, Hlozek P, Svastova P, Dvorska L, Bull T, Matlova L, et al. Identification of members of Mycobacterium avium species by Accu-Probes, serotyping, and single IS900, IS901, IS1245 and IS901-flanking region PCR with internal standards. J Microbiol Methods (2006) 64:333-45. doi:10.1016/j. mimet.2005.05.009

36. Garg SK, Tiwari RP, Tiwari D, Singh R, Malhotra D, Ramnani VK, et al. Diagnosis of tuberculosis: available technologies, limitations, and possibilities. J Clin Lab Anal (2003) 17:155-63. doi:10.1002/jcla.10086

37. Dahlhausen B, Tovar DS, Saggese MD. Diagnosis of mycobacterial infections in the exotic pet patient with emphasis on birds. Vet Clin North Am Exot Anim Pract (2012) 15:71-83,vi. doi:10.1016/j.cvex.2011.11.003

38. Saito H, Tomioka H, Sato K, Tasaka H, Dawson DJ. Identification of various serovar strains of Mycobacterium avium complex by using DNA probes specific for Mycobacterium avium and Mycobacterium intracellulare. JClin Microbiol (1990) 28:1694-7.

39. Inagaki $\mathrm{T}$, Nishimori $\mathrm{K}$, Yagi $\mathrm{T}$, Ichikawa $\mathrm{K}$, Moriyama $\mathrm{M}$, Nakagawa $\mathrm{T}$, et al. Comparison of a variable-number tandem-repeat (VNTR) method for typing Mycobacterium avium with mycobacterial interspersed repetitive-unit-VNTR and IS1245 restriction fragment length polymorphism typing. J Clin Microbiol (2009) 47:2156-64. doi:10.1128/JCM.02373-08

40. Ritelli M, Amadori M, Tagliabue S, Pacciarini ML. Use of a macrophage cell line for rapid detection of Mycobacterium bovis in diagnostic samples. Vet Microbiol (2003) 94:105-20. doi:10.1016/S0378-1135(03)00080-4

41. Tell LA, Woods L, Cromie RL. Mycobacteriosis in birds. Rev Sci Tech (2001) 20:180-203. doi:10.20506/rst.20.1.1273

42. Martin RS, Sumarah RK, Robart EM. Comparison of four culture media for the isolation of Mycobacterium tuberculosis: a 2-year study. JClin Microbiol (1975) 2:438-40.

43. Mayahi M, Mosavari N, Esmaeilzadeh S, Parvandar-Asadollahi K. Comparison of four different culture media for growth of Mycobacterium avium subsp. avium isolated from naturally infected lofts of domestic pigeons. Iran J Microbiol (2013) 5:379-82.

44. Belisle JT, Brennan PJ. Molecular basis of colony morphology in Mycobacterium avium. Res Microbiol (1994) 145:237-42. doi:10.1016/0923-2508(94) 90024-8

45. Reddy VM, Luna-Herrera J, Gangadharam PR. Pathobiological significance of colony morphology in Mycobacterium avium complex. Microb Pathog (1996) 21:97-109. doi:10.1006/mpat.1996.0046

46. Cangelosi GA, Palermo CO, Bermudez LE. Phenotypic consequences of redwhite colony type variation in Mycobacterium avium. Microbiology (2001) 147:527-33. doi:10.1099/00221287-147-3-527

47. Krzywinska E, Schorey JS. Characterization of genetic differences between Mycobacterium avium subsp. avium strains of diverse virulence with a focus on the glycopeptidolipid biosynthesis cluster. Vet Microbiol (2003) 91:249-64. doi:10.1016/S0378-1135(02)00292-4

48. Parvandar-Asadollahi K, Mosavari N, Mayahi M. Genotyping of Mycobacterium avium subsp. avium isolates from naturally infected lofts of domestic pigeons in Ahvaz by IS901 RFLP. Iran J Microbiol (2015) 7:260-4.

49. Castellanos E, Romero B, Rodriguez S, De Juan L, Bezos J, Mateos A, et al. Molecular characterization of Mycobacterium avium subspecies paratuberculosis types II and III isolates by a combination of MIRU-VNTR loci. Vet Microbiol (2010) 144:118-26. doi:10.1016/j.vetmic.2009.12.028

50. Ricchi M, Barbieri G, Cammi G, Garbarino CA, Arrigoni N. Highresolution melting for analysis of short sequence repeats in Mycobacterium avium subsp. paratuberculosis. FEMS Microbiol Lett (2011) 323:151-4. doi:10.1111/j.1574-6968.2011.02371.x
51. Ricchi M, Barbieri G, Taddei R, Belletti GL, Carra E, Cammi G, et al. Effectiveness of combination of mini-and microsatellite loci to sub-type Mycobacterium avium subsp. paratuberculosis Italian type C isolates. BMC Vet Res (2011) 7:54. doi:10.1186/1746-6148-7-54

52. Dvorska L, Bull TJ, Bartos M, Matlova L, Svastova P, Weston RT, et al. A standardised restriction fragment length polymorphism (RFLP) method for typing Mycobacterium avium isolates links IS901 with virulence for birds. J Microbiol Methods (2003) 55:11-27. doi:10.1016/S0167-7012(03)00092-7

53. Moravkova M, Lamka J, Slany M, Pavlik I. Genetic IS901 RFLP diversity among Mycobacterium avium subsp. avium isolates from four pheasant flocks. $J$ Vet Sci (2013) 14:99-102. doi:10.4142/jvs.2013.14.1.99

54. Rathnaiah G, Lamont EA, Harris NB, Fenton RJ, Zinniel DK, Liu X, et al. Generation and screening of a comprehensive Mycobacterium avium subsp. paratuberculosis transposon mutant bank. Front Cell Infect Microbiol (2014) 4:144. doi:10.3389/fcimb.2014.00144

55. Khattak FA, Kumar A, Kamal E, Kunisch R, Lewin A. Illegitimate recombination: an efficient method for random mutagenesis in Mycobacterium avium subsp. hominissuis. BMC Microbiol (2012) 12:204. doi:10.1186/1471-2180-12-204

56. Deshayes C, Laval F, Montrozier H, Daffe M, Etienne G, Reyrat JM. A glycosyltransferase involved in biosynthesis of triglycosylated glycopeptidolipids in Mycobacterium smegmatis: impact on surface properties. J Bacteriol (2005) 187:7283-91. doi:10.1128/JB.187.21.7283-7291.2005

57. Johansen TB, Agdestein A, Olsen I, Nilsen SF, Holstad G, Djonne B. Biofilm formation by Mycobacterium avium isolates originating from humans, swine and birds. BMC Microbiol (2009) 9:159. doi:10.1186/1471-2180-9-159

58. Mukherjee R, Chatterji D. Glycopeptidolipids: immuno-modulators in greasy mycobacterial cell envelope. IUBMB Life (2012) 64:215-25. doi:10.1002/ iub.602

59. Viale MN, Park KT, Imperiale B, Gioffre AK, Colombatti Olivieri MA, Moyano RD, et al. Characterization of a Mycobacterium avium subsp. avium operon associated with virulence and drug detoxification. Biomed Res Int (2014) 2014:809585. doi:10.1155/2014/809585

60. Tateishi Y, Hirayama Y, Ozeki Y, Nishiuchi Y, Yoshimura M, Kang J, et al. Virulence of Mycobacterium avium complex strains isolated from immunocompetent patients. Microb Pathog (2009) 46:6-12. doi:10.1016/j.micpath. 2008.10.007

61. Li YJ, Danelishvili L, Wagner D, Petrofsky M, Bermudez LE. Identification of virulence determinants of Mycobacterium avium that impact on the ability to resist host killing mechanisms. J Med Microbiol (2010) 59:8-16. doi:10.1099/ jmm.0.012864-0

62. Ostland VE, Watral V, Whipps CM, Austin FW, St-Hilaire S, Westerman ME, et al. Biochemical, molecular, and virulence characteristics of select Mycobacterium marinum isolates in hybrid striped bass Morone chrysops $\mathrm{x}$ M. saxatilis and zebrafish Danio rerio. Dis Aquat Organ (2008) 79:107-18. doi:10.3354/ dao01891

63. Agdestein A, Jones A, Flatberg A, Johansen TB, Heffernan IA, Djonne B, et al. Intracellular growth of Mycobacterium avium subspecies and global transcriptional responses in human macrophages after infection. BMC Genomics (2014) 15:58. doi:10.1186/1471-2164-15-58

Conflict of Interest Statement: The authors declare that the research was conducted in the absence of any commercial or financial relationships that could be construed as a potential conflict of interest.

Copyright () 2018 Zhu, Peng, Ye, Wang, Bian, Qin, Zhang and Ding. This is an open-access article distributed under the terms of the Creative Commons Attribution License (CC BY). The use, distribution or reproduction in other forums is permitted, provided the original author(s) or licensor are credited and that the original publication in this journal is cited, in accordance with accepted academic practice. No use, distribution or reproduction is permitted which does not comply with these terms. 